Article

\title{
Exceeding the Applicability Limit of Aerogel Super Insulation Materials in Different Environmental Conditions
}

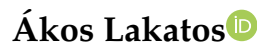 \\ Department of Building Services and Building Engineering, Faculty of Engineering, University of Debrecen, \\ H-4028 Debrecen, Hungary; alakatos@eng.unideb.hu; Tel.: +36-52-415-155 (ext. 77771)
}

Received: 9 September 2020; Accepted: 3 November 2020; Published: 4 November 2020

check for updates

Featured Application: This paper complements previous research studies executed on fiber-reinforced aerogel insulation. Here, we show that laboratory experiments executed on materials in order to see the environmentally affected changes of their thermal properties should be completed with calculations to see the application limits of the materials in proper building energetics examples.

\begin{abstract}
Newly designed and constructed buildings are subjected to increasingly strict regulations which emphasize the minimization and, where possible, the elimination of wasteful energy consumption, thus resulting in a decrease in emissions. Thermal insulation materials have an important role in making better use of the primary energy delivered to consumer systems, be it by an industrial process or building services systems or in residential and commercial buildings. It is well declared that buildings account for about $30 \%$ of total energy consumption, while they contribute to about $20 \%$ of greenhouse gas emissions. High-performance insulation has great potential to achieve the European Commission's ambitious goals for reducing the thermal loss of buildings. A new class of super insulation materials (SIMs) could play an important role in the future of insulations (e.g., fiber-reinforced silica aerogel). This material is grouped with super insulation materials by the sixty-fifth annex of the International Energy Agency. However, due to their short presence on the market, we do not know much about their long-term performance, and if their properties change with time, the question is how and in which direction they do. This is why their artificial aging is so important through thermal annealing, in addition to exposing them to high humidity and low temperatures. In this paper, the application of measurement results after the artificial aging of fiber-reinforced silica aerogel will be discussed. In order to see the changes in the thermal insulation capability of the materials, 13 different cases of environmental exposures are discussed. These cases will be presented to see possible changes in the thermal insulation performance of the aerogel after treating it in different climatic conditions. Firstly, samples were exposed to humidity treatments at $296 \mathrm{~K}$ with different relative humidities $(0,35,50,65,80$ and $90 \%)$ until they reached equilibrium moisture contents. Secondly, the samples were heat treated once for 6 weeks at $343 \mathrm{~K}$, then for 1 day at $373,423,453$ and $483 \mathrm{~K}$. Moreover, we wanted to see the effects of frost, and thus we executed a freeze-thaw cycle on the samples for 25 days between 258 and $303 \mathrm{~K}$. After these curing procedures, the thermal conductivities of the samples were measured with a heat flow meter, according to the ISO 8301 standard. The measured thermal conductivity values after heat treatment, wetting and freezing were used for building energetics calculations, with a special focus on the thermal transmittance of two different hypothetical building structures (brick- and concrete-based walls) covered with the mentioned insulation.
\end{abstract}

Keywords: super insulation materials; u-value; environmental conditions 


\section{Introduction}

Newly designed and constructed buildings are subject to increasingly strict regulations which emphasize the minimization and, where possible, the elimination of wasteful energy consumption and the resulting emissions. As a result of the emergence of an increasingly energy- and environment-conscious mindset, there is a growing demand on the consumer side for such efforts. Another significant part of energy consumption comes from transport, including vehicles. The use of thermal insulation materials is important not only in buildings, but also in aircrafts and electrical appliances [1-3]. In some cases, it is not possible to use thermal insulations with a thickness of tens of centimeters in buildings as there is not enough available space, and the external shell structure of vehicles also requires the use of a thin $(\sim \mathrm{a}$ few $\mathrm{cm})$ thickness of thermal insulation. Thanks to technological advances, the production method of thermal insulation materials has also developed. One of the most widely used thermal insulation materials in the last 20-25 years is polystyrene foam, due to its satisfactory thermal insulation capacity and relatively low cost. Recently, new materials have also appeared on the market, such as graphite-added polystyrene foam, vacuum thermal insulation panels or aerogels. Moreover, it has to be mentioned that with the development of the industry, new insulation materials are required [4-8]. These materials are also commonly referred to as advanced or nanotechnological thermal insulation materials, but are now defined as super insulation materials (SIMs). A new class of super insulating materials, such as thermal insulation materials, may play an important role in the future of insulation. It should be noted that there is no precise definition for SIMs, but Annex 65 of the International Energy Agency, Energy in Buildings and Communities Program (IEA EBC) defines the elements of the SIM group [9]. According to this annex, the following materials are part of the group: vacuum insulation panels (VIPs) and special (advanced) porous materials, such as various types of aerogels (monoliths or fibrous ones). These materials have become attractive alternatives that allow the insulation thickness to be reduced by as much as one-fifth, as well as being used as internal thermal insulation. Although these materials have excellent insulation performance, unfortunately, they are relatively expensive, and only a little information is available on their durability and long-term performance. The reason that they have relatively high prices comes from their production. To produce a monolith aerogel takes time, while creating the special circumstances for production is expensive. As such, the economical production of these flexible insulation aerogels remains a challenge [10-15]. One of the important topics of the present research is the investigation of the thermomechanical properties of the mentioned materials, including the determination of the physical properties, paying special attention to the thermal insulation performance of fibrous silica aerogel. I chose the elaboration of this topic as a task to be solved because the databases summarizing the thermal conductivity of these newly developed materials are mostly incomplete. Furthermore, their long-term performance is also unknown. It is also often the case that the thermal values given by the manufacturers do not correspond with the results obtained from the tests performed in the laboratory. Regarding insulating materials, we often do not have complete information on how they behave under external influences, such as humidity, temperature or time. These might change their properties and possibly their structures, and they may lose their good thermal insulation properties that are already present during production $[3,11,12,14-18]$.

These experiences formed the basis of the research work program and justified the transmission of the studies. Research on thermal insulation samples has included the study of thermal insulation performance through the measurement of thermal conductivity, because this parameter is the determinant of the usability of insulation materials. In the course of my research, I fully analyzed a modern (advanced or nanotechnological) but lesser known thermal insulation material (aerogel) without influences and exposed to different effects and conditions. The measurements were performed in the Building Physics Laboratory of the Faculty of Engineering at the University of Debrecen. Three cases will be presented in order to see the possible changes in the thermal insulation performance of the aerogel after treating it under different climatic (humid, icy and high temperatures reaching $\sim 523 \mathrm{~K})$ conditions. The measured thermal conductivity values after heat treatment, wetting and 
freezing will be used for building energetics calculations. One of the most important thermal (physical) characteristics of thermal insulation materials is the thermal conductivity, for which the value should be kept as low as possible after installation of the product. The elements that make up the thermal envelope of buildings can be affected by changing environmental parameters, such as humidity and temperature, and their properties can deteriorate. Laboratory testing of the thermal conductivity and moisture sorption capacity of thermal insulation materials is extremely important for engineers to be able to work with correct values during the design stage. Besides that, providing correct information on moisture uptake is also vital. Whereas previously only sorption isotherms and vapor diffusion factors were given for materials concerning moisture uptake, it is now also necessary to determine and specify the maximum water uptake, also known as the saturation moisture value, and the so-called water or vapor uptake factor. Moisture and heat affect the properties of the material, in particular its thermal conductivity. Laboratory testing of the above-mentioned parameters is widely discussed by both domestic and foreign research groups $[5-7,12,14,16,18,19]$. This paper complements previous research studies executed on the fiber-reinforced aerogel insulation $[10,11]$.

\subsection{Thermal Conductivity of Insulation Materials}

Several models exist to describe the total or effective thermal conductivity $\left(\lambda_{t}\right)$ of inhomogeneous (fibrous or cellular) thermal insulation materials described as Equation (1), one of which is the most appropriate. After the examination of the results in scientific literature [11,13] and from our research, we can also conclude that this is the most appropriate model for defining the thermal conductivity of the insulation materials. It is a basic fact that in a porous, fibrous or cellular (gas-filled) thermal insulation material, the heat propagation is divided into six members: $\left(\lambda_{c, g}\right)$, which describes the thermal conductivity of the gas; $\left(\lambda_{\mathrm{c}, \mathrm{s}}\right)$, as well as $\left(\lambda_{\mathrm{r}}\right)$, defining the radiative part; and the member defining the gas convection $\left(\lambda_{\text {conv }}\right)$, the latter being more typical for fibrous materials. Two more members describe the gas and moisture (hole) transport due to pressure differences, describing the second-order processes $\left(\lambda_{\text {hole }}, \lambda_{\text {pair }}\right)$. The effect of these holes is not taken into account in solid thermal insulation materials:

$$
\lambda_{\mathrm{t}}=\lambda_{\mathrm{c}, \mathrm{s}}+\lambda_{\mathrm{c}, \mathrm{s}}+\lambda_{\mathrm{r}}+\lambda_{\text {conv }}+\lambda_{\text {pair }}+\lambda_{\text {hole }}
$$

The total or effective thermal conductivity of the whole block material can be measured under laboratory conditions (e.g., by heat flow meter, calibrated chamber method or guarded hot plate method). The total thermal conductivity $\left(\lambda_{t}\right)$ is thus simplified to four terms as Equation (2) represents $[10,11]$ :

$$
\lambda_{t}=\lambda_{c, s}+\lambda_{c, g}+\lambda_{r}+\lambda_{\text {conv }}
$$

where $\lambda_{c, s}$ is the thermal conductivity of the solid body, appearing in the heat transfer between atoms (lattice vibrations) through the chemical bonds between atoms, $\lambda_{c, g}$ is the thermal conductivity of the gas, resulting from the collision of the gas parts and varying from molecule to molecule, $\lambda_{\mathrm{r}}$ is the radiation part, which can be connected to electromagnetic radiation from the surface of the material in the infrared range, and $\lambda_{\text {conv }}$ is the convection member, derived from the transport of thermal material or the movement of air and moisture.

For cellular materials, the convection member approaches zero with an increasing density and will be negligible. Based on this, the total thermal conductivity will be as follows (see Equation (3)) [20-23]:

$$
\lambda_{t}=\lambda_{c, s}+\lambda_{c, g}+\lambda_{r}
$$

\subsection{Thermal Conduction in Materials with Nanopores}

As the porosity of the material increases, the heat conduction through the solid skeleton decreases, because the large amount of pores limits the propagation of the phonons in the aerogel backbone. The contribution of the gas phase is due to elastic collisions between the gas molecules as it is presented in Figure 1. The thermal conductivity of the gas phase depends on the average free path length and 
the pore size of the gas molecules in the pores. For the aerogel to be an effective thermal insulator, its thermal conductivity must be lower than the conductivity of free atmospheric air $(0.025 \mathrm{~W} / \mathrm{mK}$ at $300 \mathrm{~K}$ and $1 \mathrm{~atm})$. This is achieved if the pore size is smaller than the average free path length of the air molecules ( $70 \mathrm{~nm}, 300 \mathrm{~K}$ and $1 \mathrm{~atm}$ ), thereby inhibiting the thermal diffusion of the gas (often referred to as the Knudsen effect). This is possible by pressure reduction. The ratio of the average free path of the gas molecules to the pore diameter is known as the Knudsen number. Here, the gas molecules enclosed in the pore collide with the pore wall and not with each other. For materials where the pore diameter is between 10 and $100 \mathrm{~nm}$, such as an aerogel, heat is propagated by random movement through adjacent oscillators. In these non-crystalline materials, the thermal conductivity can be three orders of magnitude lower than that of the crystalline materials.

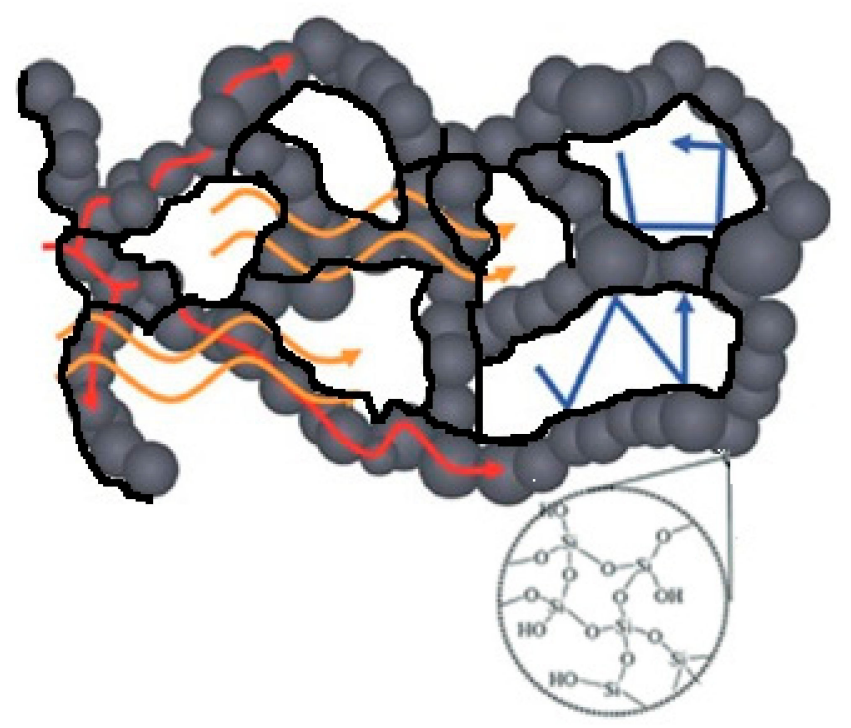

Figure 1. Different forms of heat propagation in the fiber-reinforced aerogel (nanoporous material). Red is the solid conduction, yellow is the radiative part and blue is the conduction of gas molecules. Black is the glass fiber.

It is also available in a composition optimized for different temperature ranges, in a fire-retardant design and in different thicknesses $(2-20 \mathrm{~mm})$. The contact surfaces between its particles are small. The cavities of the nanopores are smaller $(5-50 \mathrm{~nm})$ than the length of the path required for the free collision of the gas molecules within them. The gas molecules collide with the walls of the cavities, so convective heat flow is minimal. Nanopores are smaller in size than the wavelength of infrared heat rays, so their surfaces reflect and scatter most of the heat rays.

Increasing the absorption coefficient of materials at a given temperature (by adding a light-shielding or reflective additive) is an effective way to suppress the thermal radiation conductivity of $\lambda_{\mathrm{r}}$, such as a graphite additive for polystyrene, with which the effective (total) thermal conductivity can be further reduced. At the macroscopic level, the effective or total thermal conductivity mentioned above

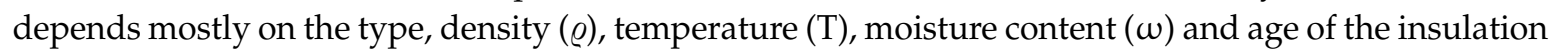
material (aging or deterioration in fibrous materials) but, of course, it also depends on the method of manufacturing. At the microscopic level, it depends on the size and arrangement of the cells and fibers, where gas filling typically plays a role. Their effects can be taken into account with correction factors, according to the MSZ EN ISO 10456: 2008 standard [24]. This standard also provides a calculation method for determining the declared (manufacturer's) value of thermal conductivity factors.

Accordingly, the effective thermal conductivity $\left(\lambda_{\text {eff }}\right)$ can be given as

$$
\lambda_{\text {eff }}=\text { funct }(\varrho ; \omega ; T ; \text { age })
$$




\subsection{Aerogel Materials as Insulation}

Aerogel materials, as it is well known, can be separated to different groups, due to their production: xerogel, aerogel, and cryogels, as they are produced at ambient pressure, supercritical drying or freeze-dried. Furthermore, they can be separated into organic, inorganic and carbon aerogels. They are usually supported by fibers such as nanocellulose, carbon, polyamide and polyester, without completeness as well as with glass. Aerogel insulations also have excellent acoustic, protective and catalytic properties. Moreover, they are used as absorbents, scaffolds, sensors and filters [25-27].

\section{Materials and Methods}

\subsection{Thermal Conductivity Test}

In order to see the changes in the thermal insulation capability of the materials, 13 different cases of environmental exposures are discussed. These cases will be presented to see possible changes in the thermal insulation performance of the aerogel after treating it in different climatic conditions. Firstly, samples were exposed to humidity treatments at $296 \mathrm{~K}$ with different relative humidities $(0,35,50,65$, 80 and $90 \%$ ) until they reached equilibrium moisture contents. Secondly, the samples were heat treated once for 7 weeks at $343 \mathrm{~K}$, then for 1 day at 373, 423, 453 and $483 \mathrm{~K}$ one after the other. Moreover, we wanted to see the effects of the frost, since we executed a freeze-thaw cycle experiment on the sample for 25 days between 258-303 K. After these curing procedures, the thermal conductivities of the samples were measured with a Holometrix Lambda 2000 type heat flow meter (HFM) (Bedford, Massachusetts, US) heat flow meter. With this device, the thermal conductivity of thermal insulation materials could be determined with acceptable accuracy, with a relative error of about $5 \%$ or less. The instrument operated according to ISO 8301 standards [28]. Materials with geometries of $30 \times 30 \times 1$ to $10 \mathrm{~cm}$ could be tested in the measuring chamber. The measurement procedures are written and presented with details in [21].

\subsection{Investigation of the Moisture Sorption Properties of Materials}

As is well known, moisture might have harmful effects on both the chemical and physical properties of building materials, due to their porous or fibrous structures. For reaching exact information about the moisture-related properties of the materials, laboratory experiments should be executed. Vapor effects on the structure mean phenomena that arise from the relationship between the structure and water vapor. Condensation is a consequence of the potential difference between the humidity of the air space and the surface temperature of the structure. Adsorption moisture is the normal state of the material, where the vapor pressure above the moisture layer bound to the surface of the cavities is in equilibrium with the vapor pressure of the air space. Vapor diffusion phenomena represent an equalization between molecules in the air space and molecules of gas in the cavities of a building material. Equilibrium moisture content is defined as absorbents absorbing or releasing moisture in media with different relative humidities. Each relative humidity corresponds to a moisture content at which the material does not absorb and release moisture. This is the equilibrium moisture content. At a given temperature, the relationship between equilibrium moisture content and relative humidity gives the sorption isotherm.

In our case, the moisture uptake properties of the materials were determined by a combination of a dryer (Venticell 111), a climate chamber (Climacell 111, MMM Medcenter Facilities GmbH, Münich, Germany) and a balance, with milligram accuracy. In connection with the determination of the moisture sorption properties of the materials, the directions of the MSZ EN ISO 12571: 2013 standard were followed $[5,10,11,29]$. After establishing the samples, the equilibrium moisture contents of their thermal conductivities were measured [11]. 


\subsection{The Tested Material}

Silica aerogel is a silica-based material that is a loose, dendritic network of silicon and oxygen atoms. During its manufacture, the liquid alcogel is carefully removed from the liquid and replaced with air to give a final product containing $99.8 \%$ air. An aerogel thermal insulation blanket is a flexible composite material that is an aerogel embedded in a fiberglass network. The production steps are as follows: (1) filling the glass fiber crosslink with the liquid-solid solution (wet-gel), (2) super-critical extraction with $\mathrm{CO}_{2}$ (drying) and (3) a dry, fiberglass-reinforced aerogel blanket (rolling).

Due to its completely harmless properties, it can be used safely in many areas of life. It is slightly compressible and plastic, so it fits well anywhere without losing its tensile strength and flexibility.

Different products have different thermal conductivities, but on average, these values are lower than the thermal conductivity of air $(0.025 \mathrm{~W} / \mathrm{mK})$, as opposed to plastic foams. The tested aerogel material presented in Figure 2, was produced by the sol-gel process with a $150 \mathrm{~kg} / \mathrm{m}^{3}$ density and a thermal conductivity of $0.013-0.025 \mathrm{~W} / \mathrm{mK}$, depending on the temperature. Due to its low thermal conductivity, it can also be used in thermal insulation in smaller thicknesses [10,11].

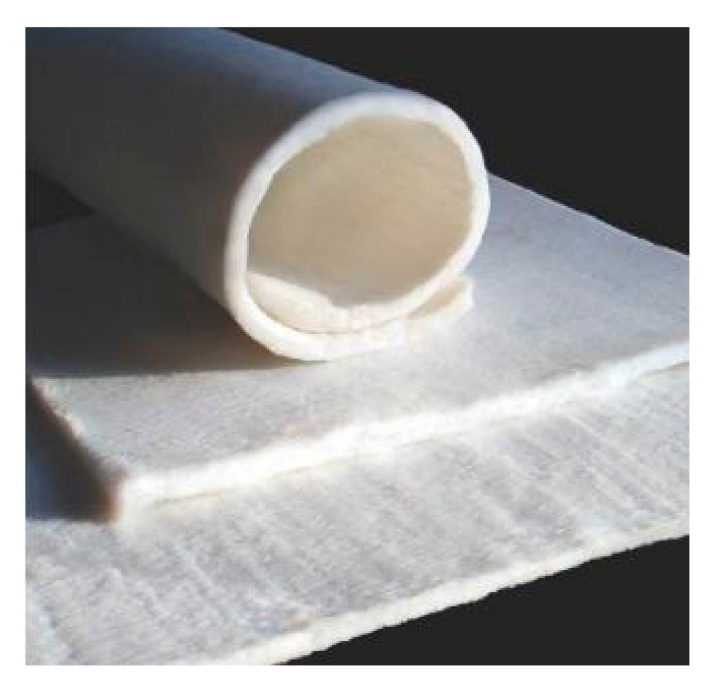

Figure 2. The tested aerogel sample.

\subsection{Aging of Materials: The Long-Term Performance}

The aging of materials is a process in which their physical, mechanical and thermal properties change over time. Aging of the material can be artificially induced by irradiation (UV or infrared) or heat treatments. The heat treatment of materials can also increase the kinetic processes that take place in them, as well as the speed of chemical and physical degradation processes within the materials. In the case of thermal insulation materials, artificial aging is usually carried out by heat treatment at $343 \mathrm{~K}$ for a longer period $[15,16,23]$. The durability of the thermal conductivity factor plays an important role in the design, both from an operational and economic point of view. Aging at higher temperatures (up to $523 \mathrm{~K}$ ) is important for materials that can also be used to insulate pipes transporting hot media (e.g., fibrous aerogel) like those in industrial settings or power plants [10].

\subsection{Moisture Sorption of Materials}

The building materials are largely porous in structure. The pores of a material and their total surface play a major role in the binding and uptake of moisture. As described above, aerogel has a nano-porous, fiber-reinforced structure. These cells, or spaces, are filled with gas (usually air), which can be displaced by moisture penetrating the material, thus adversely affecting the properties of the whole material (e.g., it can also affect the compressive strength of the material) [3,6,7]. As it was presented in the literature, moisture usually increases the thermal conductivity of the materials. It can 
be easily supported by the theory in Equation (2), where the total thermal conductivity contains the convective as well as the conductive parts of the gas. In the case of the presence of moisture among the fibers of the aerogel sample, we can expect an increase in these two thermal conductivity parts. Moisture entering the building structure can have harmful effects. It can increase the thermal conductivity of the given layer element and thus the heat transfer coefficient of the structure. The moisture uptake of the materials is typically shown on the sorption isotherm curve [10-12,22,30].

Furthermore, during the influence of moisture, not only does the thermal conductivity of the building materials change, but so do the heat storage and vapor diffusion capacity. In addition, their structural and physical properties may change, depending on the type of material. For this reason, it is important to study the moisture-absorbing properties of materials. The risk of vapor diffusion must be considered when designing containment structures [11,12].

\subsection{Effect of Frost}

Thermal insulation materials can suffer volume changes due to temperature changes, dilatation due to heat and contraction due to cold temperatures. Furthermore, for these new types of materials, such as fibrous silica aerogels, it is necessary to study how their properties change when the temperature changes rapidly. Repeated freeze-thaw cycles can cause measurable changes in the building or the material structure. In addition, freezing can generate internal stresses in the material. Frost damage is caused by freezing of the moisture in the material. It can cause cracks as well as swelling of the structural element. Several freeze-thaw cycles can provoke an accumulation of microcracks. Frost protection is particularly important for the durability and insulation of building components. In the case of frost protection, special attention must be paid to the effects of meteorological humidity and the groundwater on the building. The evaporation of groundwater and precipitation reduce the thermal insulation capability of building structures. Furthermore, it can cause irreparable damages. This can be prevented by using frost-proof materials. In order to see the effects of the frost and the thaw in the aerogel sample, we executed some experiments. The freeze-thaw cycle was executed between $258 \mathrm{~K}$ and $303 \mathrm{~K}$ [11].

\section{Results}

\subsection{Prelude of the Results}

\subsubsection{Thermal Annealing: Cases A0-A5}

In the Venticell 111 dryer, heat treatment tests were performed on samples that were $30 \mathrm{~cm} \times 30 \mathrm{~cm}$ and $1 \mathrm{~cm}$ thick. I performed two series of heat treatments, during which I measured the thermal conductivity factors in each stage and followed the changes in the physical and thermal engineering characteristics. The samples were heat treated at $343 \mathrm{~K}$ for 6 weeks in a Venticell 111 dryer at atmospheric pressure, and then the thermal conductivity coefficients were measured. I found that the results fluctuated around an average reading $(0.0171 \mathrm{~W} / \mathrm{mK})$, which corresponds to the thermal conductivity of the above-mentioned fully dried to constant weight (as-received) sample; this measurement value became A0. For the same period $(24 \mathrm{~h})$, but at different temperatures, I heat treated the same sample with the Venticell 111 and then measured the change in thermal conductivity for each temperature. I treated the samples first at $373 \mathrm{~K}$ for 1 day, then at $423 \mathrm{~K}$ for 1 day, at $453 \mathrm{~K}$ for 1 day and finally at $483 \mathrm{~K}$ for 1 day. The reached thermal conductivities were assigned as A1, A2, A3, A4 and A5, respectively. The thermal conductivity factors are shown in Figure 3. 


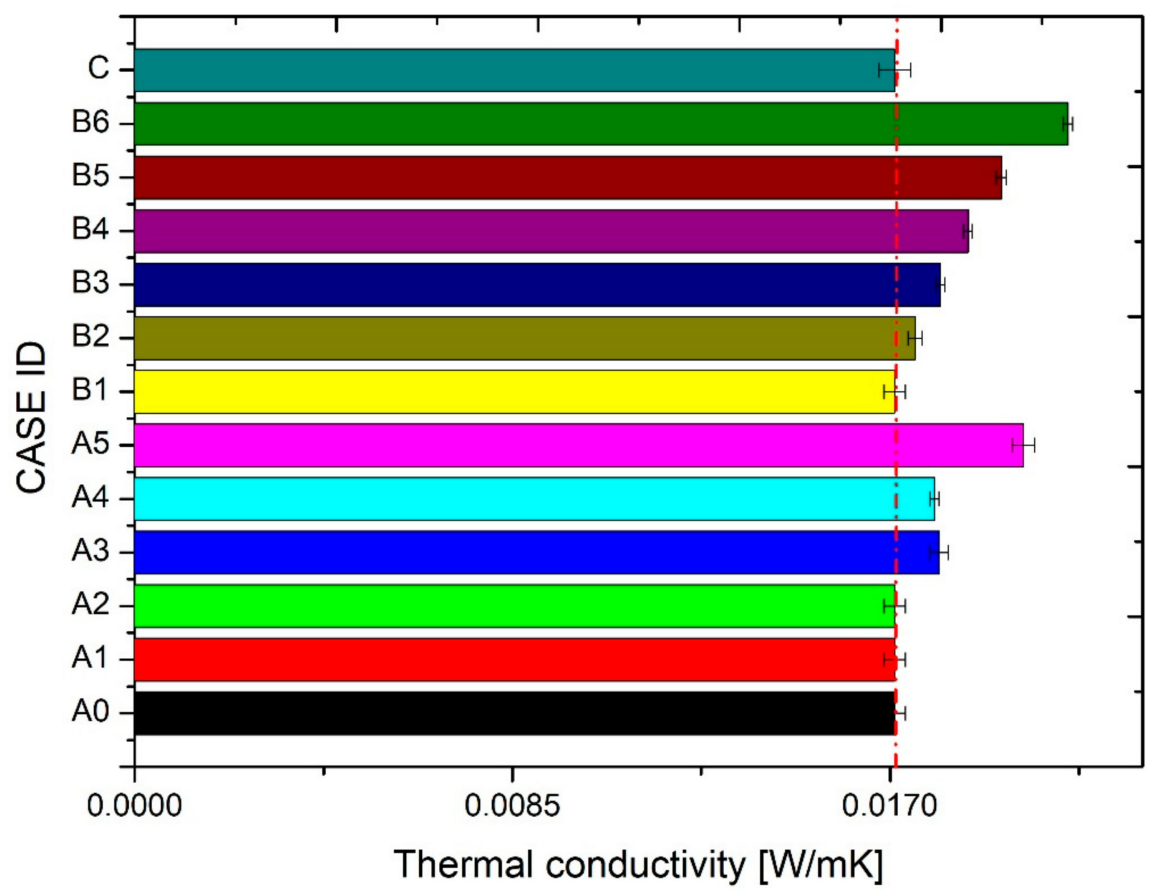

Figure 3. The measured thermal conductivities.

Apparently, the thermal conductivity of the sample was stable up to $373 \mathrm{~K}$, and then it increased with the increasing temperature [10]. Results presented by Miros in [16] and by Jelle in [30] showed that thermal annealing had as significant effect as artificial ageing both in structural and thermal properties of materials.

Previously in [31], structural changes in the samples were revealed after the heat treatments. For clarity purposes, this paper only highlights them.

The following changes were observed after heat treatment and were presented in [31]:

- Crystallization and grain growth processes were revealed by X-ray diffractometry;

- Grain separation, as well as the growth of the grains, were manifested with a scanning electron microscope;

- Changes in the sorption isotherm were evinced, showing increasing moisture sorption after heat treatments;

- The decrease in density with increasing specific heat was also determined by calorimetry.

The study by Iswar and colleagues [32] presented well how the results of the structural changes of the materials by thermal annealing could be followed well by X-ray diffraction. They reached a similar phenomenon to that presented earlier in [31], showing that the aerogel grains separated down from the fibers and, at the same time, cracks appeared and the crystallization process took place.

\subsubsection{Moisture's Effects: Cases B1-B6}

Berardi in [12] showed that, besides thermal annealing and UV irradiation, treatment of the aerogel samples in a climatic chamber is supposedly also a good method for seeing changes in the thermal properties of the materials after varying the environmental conditions. It was well stated earlier that moisture affects the thermal conductivity of aerogel samples $[6,7,12,14]$. In our case, laboratory measurements were executed in order to show the changes caused by the wetting of the samples.

The thermal conductivities of the samples were measured after drying them to changeless weights and wetting them in the climatic chamber (Climacell) for one day at $296 \mathrm{~K}$ and at 35, 50, 65, 80 and $90 \%$ relative humidity. The measured moisture contents are highlighted in the function of the relative 
humidity in Table 1, while their thermal conductivities are represented in Figure 3. These cases were assigned as B1-B6 [10]. It was reported in [33-35] that investigations of the thermal properties of materials in different climatic conditions are very important.

Table 1. Moisture contents in the function of relative humidity.

\begin{tabular}{ccc}
\hline Relative Humidity (\%) at $\mathbf{2 9 6} \mathbf{K}$ & Equilibrium Moisture Content (\%) & Standard Deviation, $\pm(\mathbf{\%})$ \\
\hline 0 & 0 & 0 \\
35 & 0.9 & 0.031 \\
50 & 1.5 & 0.025 \\
65 & 2 & 0.031 \\
80 & 2.25 & 0.077 \\
90 & 3.5 & 0.093 \\
\hline
\end{tabular}

\subsubsection{Effects of Freezing: Case C}

As mentioned above, freezing can cause harmful effects in the structure of the building materials. In [12], where temperature fluctuations were applied on aerogel samples between $243 \mathrm{~K}$ and $313 \mathrm{~K}$, it was highlighted that these kinds of treatments of the samples could cause fatigue in the samples. It was also stated that it had only a slight impact on the thermal conductivity. In order to investigate whether freezing could cause any change in the thermal conductivity of the material, the aerogel sample was treated at $258 \mathrm{~K}$ at $60 \%$ relative humidity in a cold room for 25 days. After a few days, the sample was taken out of the cold room and its thermal conductivity was measured at $303 \mathrm{~K}$. I found that the thermal conductivity coefficient fluctuated around a constant value $(0.0173 \mathrm{~W} / \mathrm{mK})$, so it could be considered constant, and it had good correlations with the results presented in [12]. During the presentation of further results, it will be assigned as Case C in Figure 3 and after [11].

For the calculations to see the above-mentioned environmentally affected changes in thermal conductivity, each case was assigned with a label. These labels are shown in Table 2, and they will be referred to accordingly in further calculations.

Table 2. A highlight of the cases.

\begin{tabular}{cc}
\hline CASE ID & Environmental Condition \\
\hline A0 & Annealed at $343 \mathrm{~K}$ for 42 days \\
A1 & Annealed at $343 \mathrm{~K}$ for 1 day \\
A2 & Annealed at $373 \mathrm{~K}$ for 1 day \\
A3 & Annealed at $423 \mathrm{~K}$ for 1 day \\
A4 & Annealed at $453 \mathrm{~K}$ for 1 day \\
A5 & Annealed at $483 \mathrm{~K}$ for 1 day \\
B1 & $296 \mathrm{~K} 0 \% \mathrm{RH}$ \\
B2 & $296 \mathrm{~K} 30 \% \mathrm{RH}$ \\
B3 & $296 \mathrm{~K} 50 \% \mathrm{RH}$ \\
B4 & $296 \mathrm{~K} 65 \% \mathrm{RH}$ \\
B5 & $296 \mathrm{~K} 80 \% \mathrm{RH}$ \\
B6 & $296 \mathrm{~K} 90 \% \mathrm{RH}$ \\
C & $258 \mathrm{~K} 25 \mathrm{days}$ \\
\hline
\end{tabular}

In Figure 3, the results of the thermal conductivity measurements with the estimated errors ( \pm deviance from the averages as absolute values) can be found. The results were obtained using Holometrix Lambda heat flow meter equipment $[10,11]$. The starting thermal conductivity value belonging to the as-received sample $(0.0171 \mathrm{~W} / \mathrm{mK})$ is indicated by the red dashed line. One can see that three values, denoted as A5, B5 and B6 and belonging to thermal annealing at $483 \mathrm{~K}$ for 1 day and for humidity treatments at $296 \mathrm{~K}$ for 80 to $90 \%$ relative humidity, respectively, jump out, while A0-3, $\mathrm{B} 1$ and $\mathrm{C}$ remain constant. Furthermore, the rest of the results have slight changes. 


\subsection{Practical Application of the Results}

In order to see the practical applications of the revealed effects of both thermal annealing and sorption properties, as well as freezing, on thermal conductivity, overall thermal transmittance values were calculated for two hypothetical cases. Firstly, a suspected wall structure was created with $0.4 \mathrm{~cm}$ of brick and another with $0.4 \mathrm{~cm}$ of concrete, having 0.72 and $0.70 \mathrm{~W} / \mathrm{mK}$ thermal conductivities, respectively. For calculating the $\mathrm{U}$-value $\left(\mathrm{m}^{2} \mathrm{~K} / \mathrm{W}\right)$, the following equation was used:

$$
\mathrm{U}=1 /\left(\left(1 / \alpha_{\mathrm{i}}\right)+\Sigma(\mathrm{d} / \lambda)+\left(1 / \alpha_{\mathrm{e}}\right)\right)
$$

where $\mathrm{d}$ is the layer thickness, $\lambda$ is the thermal conductivity and $\alpha_{\mathrm{i}}$ and $\alpha_{\mathrm{e}}$ are the surface heat transfer coefficients. In our case, these were 8 and $24 \mathrm{~m}^{2} \mathrm{~K} / \mathrm{W}$, respectively. Moreover, plasters were also counted on both sides, with $2.5 \mathrm{~cm}$ thicknesses and having thermal conductivities of $0.9 \mathrm{~W} / \mathrm{mK}$. For these hypothetical constructions, the initial value for the thermal transmittance $\mathrm{U}_{\mathrm{o}}$ for the brick was 1.29, while for the concrete it was $1.26 \mathrm{~W} / \mathrm{m}^{2} \mathrm{~K}$ without any insulation. For the first case, both wall structures (brick and concrete) were theoretically insulated with $1 \mathrm{~cm}$ thick aerogel insulation, starting with the initial $0.017 \mathrm{~W} / \mathrm{mK}$ thermal conductivity. This thickness was chosen because the original as-received tested aerogel, provided by the manufacturer, had a thickness of $1 \mathrm{~cm}$.

Figure 4 presents the calculated thermal transmittances for the brick and concrete walls having $1 \mathrm{~cm}$ of aerogel insulation.

a

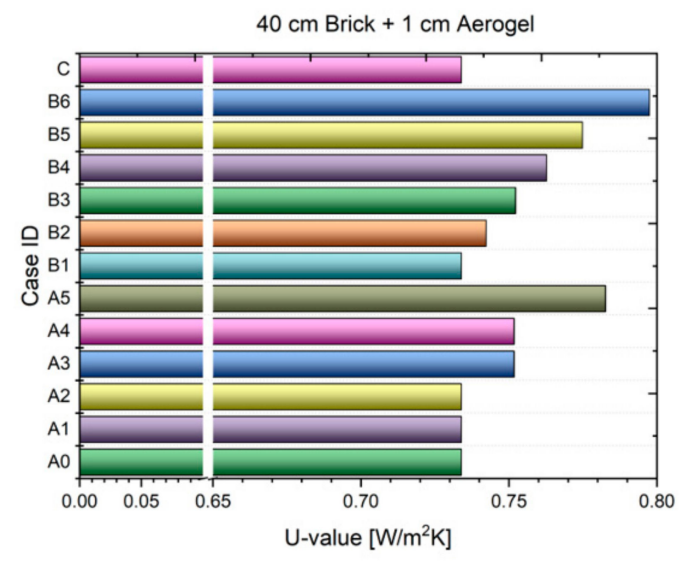

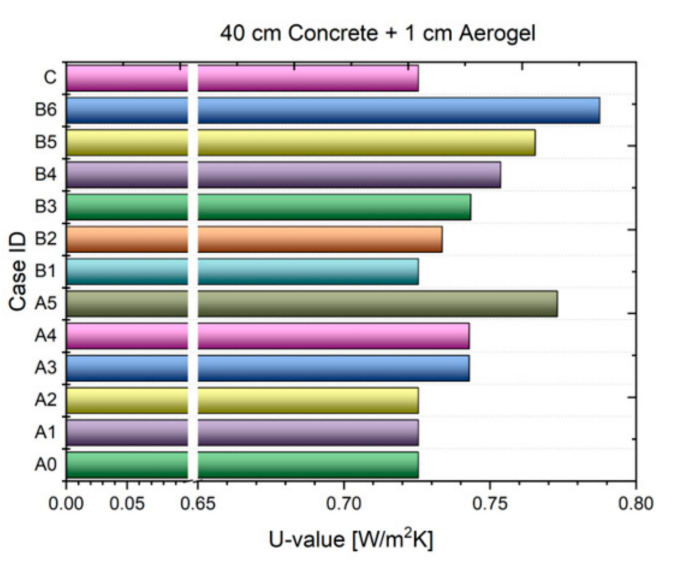

Figure 4. The hypothetical structures of (a) brick with $1 \mathrm{~cm}$ of aerogel and (b) concrete with $1 \mathrm{~cm}$ of aerogel.

Starting from Figure 3, presented above, we can observe salient peaks for Cases A5, B5 and B6, while A0, A1, A2 and B1 remained constant for both cases. A slight increase can be observed by A3, A4, $\mathrm{B} 2, \mathrm{~B} 3$ and B4. These values mirror the thermal conductivity results well, too. As a base of those values, we can declare the following (trivial) phenomenon: increasing thermal conductivity increases the U-value. To go deeper into these energetics calculations, another structure pair was also investigated.

Another calculation row was executed using the measured thermal conductivities, where the initial thermal transmittance was fixed at $\mathrm{U}=0.24 \mathrm{~W} / \mathrm{m}^{2} \mathrm{~K}$. These values were chosen because in Hungary, the building energetics requirement for the nearly zero buildings is $0.24 \mathrm{~W} / \mathrm{m}^{2} \mathrm{~K}$ (see Figure 5). 
a

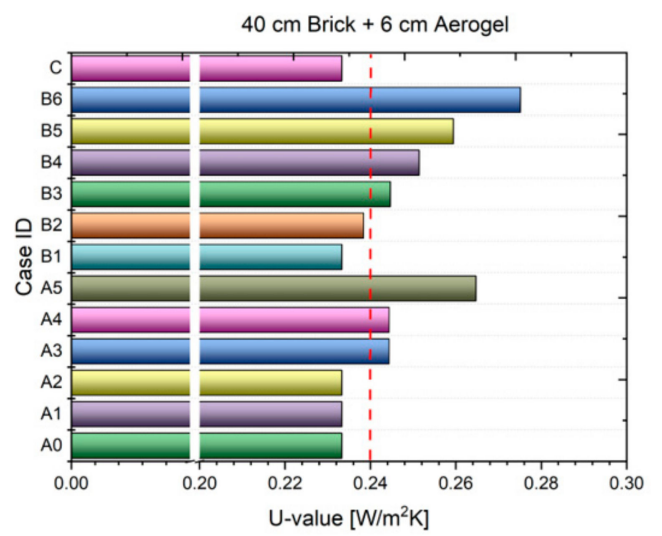

b

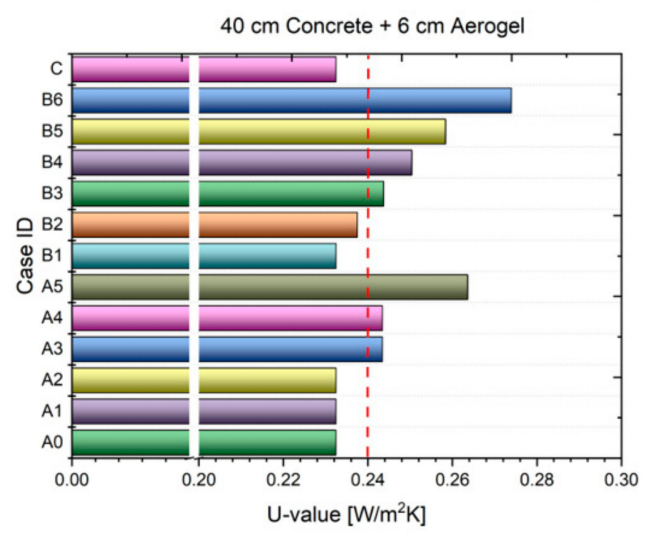

Figure 5. The structure with $\mathrm{U}=0.24 \mathrm{~W} / \mathrm{m}^{2} \mathrm{~K}$ thermal transmittance. (a) Brick with $6 \mathrm{~cm}$ of aerogel and (b) concrete with $6 \mathrm{~cm}$ of aerogel.

One goal of this paper is to present a sensitivity analysis regarding the U-value. It was first calculated that, for a $40 \mathrm{~cm}$ brick or concrete system covered (theoretically) with $2.5 \mathrm{~cm}$ thick plaster on both sides, $6 \mathrm{~cm}$ of aerogel with $(0.0171 \mathrm{~W} / \mathrm{mK})$ insulation would be needed to fulfill the requirement, since this thickness was fixed for the calculations. In Figure 5, this $\mathrm{U}=0.24 \mathrm{~W} / \mathrm{m}^{2} \mathrm{~K}$ was highlighted with a red dashed line. Following Figure 3, as well as Figure 4a,b, one can observe the similar noticeable cases. The outstanding results belong to Cases A5, B5 and B6, while A3, A4 and B2, as well as B3 and $\mathrm{B} 4$, had only mild protrusion from the background $\left(\mathrm{U}=0.24 \mathrm{~W} / \mathrm{m}^{2} \mathrm{~K}\right)$ value.

After this, with a percentile calculation, we analyzed which case results exceeded $U=0.24 \mathrm{~W} / \mathrm{m}^{2} \mathrm{~K}$. These changes are presented in Figure 6.

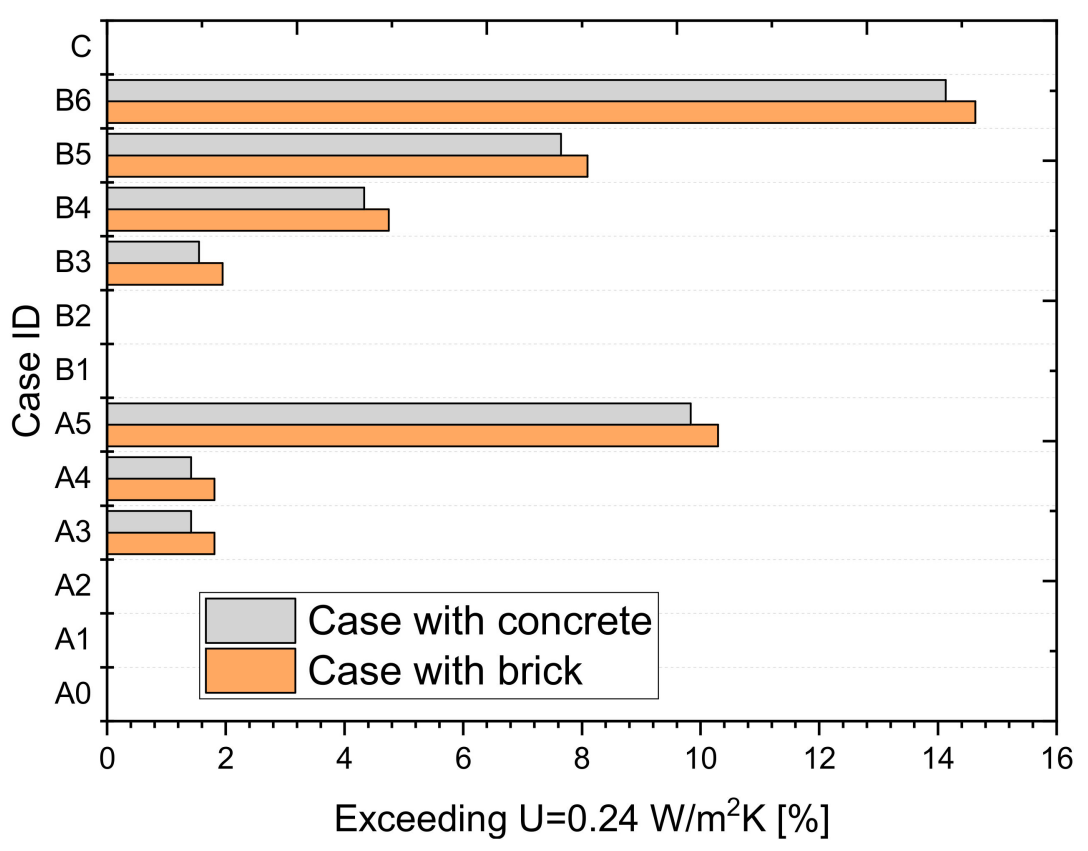

Figure 6. The percentile changes in the $U$-value, compared with $U=0.24 \mathrm{~W} / \mathrm{m}^{2} \mathrm{~K}$.

From Figure 6, one can see that two cases, the values belonging to thermal annealing at $483 \mathrm{~K}$ for 1 day and for humidity treatment at $296 \mathrm{~K}$ and for $90 \%$ relative humidity, resulted in more than $10 \%$ increases (A5 and B6), in which B6 belonged to the wetted sample, causing a high moisture load and increasing the U-value by about $15 \%$. A1 and A2 (sample annealed at $343 \mathrm{~K}$ for 1 day and annealed at $373 \mathrm{~K}$ for 1 day) kept the requirement. however, $\mathrm{A} 3$ and $\mathrm{A} 4$ broke it, belonging to the heat treatment 
at $423 \mathrm{~K}$ for 1 day and at $453 \mathrm{~K}$ for 1 day, respectively, and presenting artificial aging. The results, referring to the wetted samples as B3, B4 and B5 (from values belonging to humidity treatment at $296 \mathrm{~K}$ and $50 \%, 65 \%$ and $80 \%$ relative humidities, respectively), show a monotonous increase, scrubbed from below the $10 \%$ change.

\section{Conclusions}

During the existence of a building, a lot of influences affect its external structure and materials. From the energy point of view, the most significant effect is the periodic or rapid change in outside temperature. This gives an order of magnitude of how much heat load or heat demand the building will have. A moisture load, due to relative humidity, also has an effect that could be detected in a building in terms of the U-value, specific heat loss coefficient, heat storage capacity or energy consumption. Moisture's effects happen over a long period of time, mostly on rainy days and during transition periods. The building is also affected by wind, and it has a constant cooling and heating effect throughout the year. Furthermore, the properties of the materials deteriorate due to time (age), which can be simulated well by heat annealing. Due to technological advances, the manufacturing technology of materials has expanded. In recent years, new materials have also appeared on the market, such as graphite-added polystyrene foam or aerogel, as well as vacuum insulation panels.

In this paper, the nature of various effects of the listed phenomena on the thermal conductivity of aerogel insulation were examined, and the measured data were used for thermal transmittance calculations. The following results were reached after wetting the samples at $296 \mathrm{~K}$ from 30 to $90 \%$ relative humidity and thermally annealing them for 1 day at a 343-483 K temperature range, as well as after freezing the samples from 1 to 25 days at $258 \mathrm{~K}$ :

- With an increasing moisture load, the thermal conductivity can be increased, since the thermal performance of the structure can be reduced. A moisture content of $1-5 \%$ sorbed into the insulation can result in up to approximately a $20 \%$ decrease in the thermal performance of the wall structure. We showed that for a relative humidity over $65 \%$ at $296 \mathrm{~K}$, the high moisture exposure reduced the thermal insulation capability since it increased the U-value.

- Thermal annealing as artificial aging can simulate the lifetimes of the materials well. Annealing the samples up to $523 \mathrm{~K}$ can also result in a significant reduction in the thermal insulating performance of both the material and the structure. Along with this, at lower temperatures (around $423 \mathrm{~K}$ ), the appearing kinetic changes enhance the thermal conductivity, too.

- Aerogel exposed to short term freezing and thawing cycles (1-25 days and 258 K) might not cause deteriorating effects in the thermal performance of the building. Let me mention that this is expectable from good and so-called super insulation materials.

Funding: This research was funded by the Ministry of Innovation and Technology in Hungary, grant number NKFIH-1150-6/2019.

Acknowledgments: The research was financed by the Higher Education Institutional Excellence Program (NKFIH-1150-6/2019) of the Ministry of Innovation and Technology in Hungary, within the framework of the Energy thematic program of the University of Debrecen.

Conflicts of Interest: The author declares no conflict of interest. The funders had no role in the design of the study; in the collection, analyses, or interpretation of data; in the writing of the manuscript, or in the decision to publish the results.

\section{References}

1. Cheng, Z.; Li, X.; Li, Z.; Si, J.; Xu, S.; Nie, R. Optimal scheduling strategy of building integrated photovoltaic microgrid considering virtual energy storage. Appl. Sci. 2020, 10, 6176. [CrossRef]

2. Huang, B.; Lu, W. Experimental Investigation of the multi-physical properties of an energy efficient translucent concrete panel for a building envelope. Appl. Sci. 2020, 10, 6863. [CrossRef] 
3. Kočí, V.; Jerman, M.; Pavlík, Z.; Maděra, J.; Žák, J.; Černý, R. Interior thermal insulation systems based on wood fiberboards: Experimental analysis and computational assessment of hygrothermal and energy performance in the Central European climate. Energy Build. 2020, 222, 110093. [CrossRef]

4. Zach, J.; Novák, V.; Peterková, J.; Bubeník, J. Development of vacuum insulation panels with utilization of organic by-products. Energies 2020, 13, 1165. [CrossRef]

5. Török, L. Industry 4.0 from a few aspects, in particular, in respect of the decision making of the Management/Will the new industrial revolution change the traditional management functions. Int. Rev. Appl. Sci. Eng. 2020, 11, 140-146.

6. Ihara, T.; Jelle, B.P.; Gao, T.; Gustavsen, A. Aerogel granule aging driven by moisture and solar radiation. Energy Build. 2020, 103, 238-248. [CrossRef]

7. Stahl, T.; Brunner, S.; Zimmermann, M.; Ghazi Wakili, K. Thermo-hygric properties of a newly developed aerogel based insulation rendering for both exterior and interior applications. Energy Build. 2012, 44, 114-117. [CrossRef]

8. Zach, J.; Peterková, J.; Dufek, Z.; Sekavčnik, T. Development of vacuum insulating panels (VIP) with non-traditional core materials. Energy Build. 2019, 199, 12-19. [CrossRef]

9. IEA Annex 65 International Energy Agency (IEA). Energy in Buildings and Communities (EBC) Annex 65 "Long-Term Performance of Super-Insulating-Materials (SIM) in Building Components and Systems"-Report of Subtask I: State of the Art and Case Studies; IEA: Paris, France, 2020.

10. Lakatos, Á. Stability investigations of the thermal insulating performance of aerogel blanket. Energy Build. 2019, 139, 506-516. [CrossRef]

11. Lakatos, Á. Investigation of the thermal insulation performance of fibrous aerogel samples under various hygrothermal environment: Laboratory tests completed with calculations and theory. Energy Build. 2020, 2020 214, 109902. [CrossRef]

12. Berardi, U.; Nosrati, R.H. Long-term thermal conductivity of aerogel-enhanced insulating materials under different laboratory aging conditions. Energy 2018, 147, 1188-1202. [CrossRef]

13. Jelle, B.P. Traditional, state-of-the-art and future thermal building insulation materials and solutions-properties, requirements and possibilities. Energy Build. 2011, 43, 2549-2563. [CrossRef]

14. Ibrahim, M.; Wurtz, E.; Biwole, P.H.; Achard, P.; Salle, H. Hygrothermal performance of exterior walls covered with aerogel-based insulating rendering. Energy Build. 2014, 84, 241-251. [CrossRef]

15. Berardi, U.; Zaidi, S. Characterization of commercial aerogel-enhanced blankets obtained with supercritical drying and of a new ambient pressure drying blanket. Energy Build. 2019, 198, 542-552. [CrossRef]

16. Miros, A. Thermal aging effect on thermal conductivity properties of mineral wool pipe samples at high temperature. In Proceedings of the 3rd World Congress on Mechanical, Chemical and Material Engineering (MCM'17), Rome, Italy, 8-10 June 2017. [CrossRef]

17. Miros, A.; Psiuk, B.; Szpikowska-Sroka, B. Aerogel insulation materials for industrial installation: Properties, and structure of new factory-made products. J. Sol Gel Sci. Technol. 2017, 84, 496-506. [CrossRef]

18. Pedroso, M.; Flores-Colen, I.; Silvestre, J.D.; Gomes, M.G. Nanomaterials' influence on the performance of thermal insulating mortars-A statistical analysis. Appl. Sci. 2020, 10, 2219. [CrossRef]

19. Pereira, M.C.; Soares, A.; Flores-Colen, I.; Correia, J.R. Influence of exposure to elevated temperatures on the physical and mechanical properties of cementitious thermal mortars. Appl. Sci. 2020, 10, 2200. [CrossRef]

20. Jelle, B.P.; Tao, G.; Ingunn, S.L.; Bente, T.; Grandcolas, M.; Gustavsen, A. Thermal superinsulation for building applications - From concepts to experimental investigations. Int. J. Struct. Eng. Des. 2014, 1, 43-50.

21. Lakatos, Á. Thermal conductivity of insulations approached from a new aspect. J. Therm. Anal. Calorim. 2018, 133, 329-335. [CrossRef]

22. Kočí, J.; Kočí, V.; Maděra, J.; Rovnaníková, P.; Černý, R. Computation analysis of hygrothermal performance of renovation renders. In Advanced Computational Methods and Experiments in Heat Transfer XI; Sunded, B., Brebbia, C.A., Mander, U., Eds.; WIT Press: Ashurts, UK, 2010; pp. 267-277.

23. Koru, M. Determination of thermal conductivity of closed-cell insulation materials that depend on temperature and density. Arab. J. Sci. Eng. 2016, 41, 4337-4346. [CrossRef]

24. EN ISO 10456: 277. Standard: Building Materials and Products. Hygrothermal Properties. Tabulated Design Values and Procedures for Determining Declared and Design Thermal Values; Standards Policy and Strategy Committee: Brussels, Belgium, 2007. 
25. An, L.; Wang, J.; Petit, D.; Armstrong, J.; Li, C.; Hu, Y.; Huang, Y.; Shao, Z.; Ren, S. A scalable crosslinked fiberglass-aerogel thermal insulation composite. Appl. Mater. Today 2020, 21, 100843. [CrossRef]

26. Kucharek, M.; Macrae, W.; Yuang, L. Investigation of the effects of silica aerogel particles on thermal and mechanical properties of epoxy composites. Compos. Part A Appl. Sci. Manuf. 2020, 139, 106108. [CrossRef]

27. Yiang, S.; Zhang, M.; Jiang, W.; Xu, Q.; Yu, J.; Liu, L.; Liu, L. Multiscale nanocelluloses hybrid aerogels for thermal insulation: The study on mechanical and thermal properties. Carbohydr. Polym. 2020, 247, 116701.

28. EN ISO 8301:1991. Thermal Insulation-Determination of Steady-State Thermal Resistance and Related Properties-Heat Flow Meter Apparatus; The European Committee for Standardization: Brussels, Belgium, 1991.

29. ISO 12571:2013. Hygrothermal Performance of Building Materials and Products-Determination of Hygroscopic Sorption Properties; ISO: Geneva, Switzerland, 2013.

30. Jelle, B.P. Accelerated climate ageing of building materials, components and structures in the laboratory. J. Mater. Sci. 2012, 47, 6475-6496. [CrossRef]

31. Lakatos, A.; Csik, A.; Trnik, A.; Budai, I. Effects of the heat treatment in the properties of fibrous aerogel thermal insulation. Energies 2019, 12, 12102001. [CrossRef]

32. Iswar, S.; Griffa, M.; Kaufmann, R.; Beltran, M.; Huber, L.; Brunner, S.; Lattuada, M.; Koebel, M.M.; Malfait, W.J. Effect of aging on thermal conductivity of fiber-reinforced aerogel composites: An X-ray tomography study. Microporous Mesoporous Mater. 2019, 278, 289-296. [CrossRef]

33. Kočí, J.; Fořt, J.; Černý, R. Energy efficiency of latent heat storage systems in residential buildings: Coupled effects of wall assembly and climatic conditions. Renew. Sust. Energy Rev. 2020, 132, 110097. [CrossRef]

34. Novak, V.; Zach, J. Study of the efficiency and durability of hydrophobization modifications of building elements. IOP Conf. Ser. Mater. Sci. Eng. 2019, 583, 012032. [CrossRef]

35. Zhu, J.; Zhao, F.; Xiong, R.; Peng, T.; Ma, Y.; Hu, J.; Xie, L.; Jiamg, C. Thermal insulation and flame retardancy of attapulgite reinforced gelatin-based composite aerogel with enhanced strength properties. Compos. Part A Appl. Sci. Manuf. 2020, 138, 106040. [CrossRef]

Publisher's Note: MDPI stays neutral with regard to jurisdictional claims in published maps and institutional affiliations.

(C) 2020 by the author. Licensee MDPI, Basel, Switzerland. This article is an open access article distributed under the terms and conditions of the Creative Commons Attribution (CC BY) license (http://creativecommons.org/licenses/by/4.0/). 